\title{
Discrete subpulmonic membrane in association with isolated severe pulmonary valvar stenosis
}

\author{
Endale Tefera $^{1 *}$, Ramón Bermudez-Cañete ${ }^{2}$ and Lola Rubio ${ }^{3}$
}

\begin{abstract}
Background: Subpulmonic membrane as a cause of right ventricular outflow tract obstruction in patients with concordant ventriculoarterial connection and intact ventricular septum is considered to be rare.

Case presentation: A 7 - year - old boy was referred to a tertiary care hospital with complaints of dyspnea on moderate exertion and palpitations of about 2 years duration. Physical examination revealed parasternal lift, systolic thrill and a $4 / 6$ ejection systolic murmur, best heard over the left $2^{\text {nd }}$ intercostal space. His oxygen saturation was $88 \%$ on room air. Two-dimensional echocardiography showed a thickened pulmonary valve with fused leaflets that show severe systolic doming. There was a discrete subpulmonic membrane about $1.3 \mathrm{~cm}$ below the pulmonary valve annulus. Continuous wave Doppler interrogation showed peak systolic pressure gradient of $185 \mathrm{mmHg}$ across the pulmonary valve. Balloon dilation of the pulmonary valve was performed and the pressure gradient came down to $50 \mathrm{mmHg}$. Follow-up transthoracic echocardiography showed residual pressure gradient of about $50-60$ $\mathrm{mmHg}$ across the pulmonary valve. The residual pressure gradient appeared to be mainly subvalvar, as seen on the continuous wave Doppler tracing. The patient reported marked improvement in terms of exercise tolerance and subjective symptoms.

Conclusions: Association of subpulmonic membrane with severe pulmonary valvar stenosis, concordant ventriculoarterial connection and intact ventricular septum is rare. When it occurs, the result of percutaneous valve dilation may be suboptimal.
\end{abstract}

Keywords: Subpulmonic membrane, Right ventricular outflow, Pulmonary stenosis, Percutaneous valvotomy

\section{Background}

Membranous subpulmonic stenosis in association with supracristal ventricular septal defect or with ventricular septal defect and aortic regurgitation has been reported in recent literature [1,2]. Subpulmonic membrane in patients with corrected transposition of the great arteries has also been reported and in this setting it has also been mentioned that percutaneous balloon dilation of the membranous obstruction was effective [3]. Isolated subpulmonic membrane causing critical neonatal subpulmonic stenosis has also been described [4]. However, subpulmonic membrane in association with isolated pulmonary valvular stenosis is not well described at least to our knowledge.

\footnotetext{
* Correspondence: endalet2008@gmail.com

'Department of Pediatrics \& Child Health, School of Medicine, Addis Ababa, University \& Cardiac Center, Addis Ababa, Ethiopia

Full list of author information is available at the end of the article
}

\section{Case presentation}

We report a 7 year old boy who was referred to the Cardiac Center in Addis Ababa with dyspnea on moderate exertion and palpitations of about 2 years duration. The child was found to have a cardiac murmur at the age of about 2 years but was not subjected to echocardiography due to lack of skill and equipment in his locality. He was not on any medication at the time of presentation.

On physical examination, he appeared to be wellgrown and healthy-appearing boy with a weight of $39 \mathrm{~kg}$, height of $132 \mathrm{~cm}$ and body mass index of 22.4 . His blood pressure was $127 / 55 \mathrm{mmHg}$ and his pulse rate was $84 \mathrm{bpm}$. His oxygen saturation was $88 \%$ on room air. There was no remarkable cyanosis or clubbing of the fingers. Peripheral pulses were palpable. He had a parasternal lift, systolic thrill and a 4/6 ejection systolic murmur, best heard over the left $2^{\text {nd }}$ intercostal space and a pansystolic murmur of grade 3/6 intensity, best heard

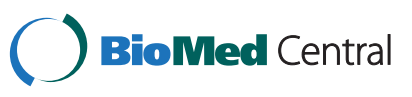


over the left lower sternal border. There was no hepatomegaly or peripheral edema.

His chest $\mathrm{X}$ - ray showed marked cardiac enlargement with clearly decreased pulmonary vascular markings. The electrocardiogram showed sinus rhythm with a rate of 88 beats per minute, incomplete right bundle branch block, right ventricular hypertrophy, right atrial enlargement and right axis deviation. Echocardiographic examination showed normal abdominal and atrial situs, with normal position of the heart in the left chest and normal venoatrial, atrioventricular and ventriculoarterial relationships. The right ventricle looked markedly dilated and hypertrophied. The right atrium looked dilated. Right ventricular systolic function appeared grossly reduced on visual inspection and Tricuspid Annular Plane Systolic Excursion (TAPSE). There was a patent foramen ovale with right to left flow by color Doppler. The interventricular septum appeared intact. The mitral and aortic valves were structurally normal. The tricuspid valve looked thickened. The pulmonary valve was thickened with fused leaflets. No calcification was seen. There was a trickle of flow seen across the valve. There was a discrete circumferential membrane about $1.3 \mathrm{~cm}$ below the pulmonic valve (Figure 1). Continuous wave Doppler across the pulmonic valve showed a peak systolic pressure gradient of $185 \mathrm{mmHg}$. However, pulsed wave
Doppler just distal to the membrane did not show significant turbulence or pressure gradient before dilation of the valve. He had also moderate tricuspid regurgitation with pressure gradient of $185 \mathrm{mmHg}$. No pericardial effusion was seen.

The boy was scheduled for percutaneous balloon dilation of the valve under general anesthesia and was taken to the catheterization laboratory. Right ventriculography in the frontal projection showed a discrete membranous obstruction about $1.3 \mathrm{~cm}$ below the pulmonic valve (Figure 2). Right ventricular systolic pressure was $160 \mathrm{mmHg}$ and the pulmonary arterial systolic pressure was $15 \mathrm{mmHg}$. With a $17 \mathrm{~mm} \times$ $30 \mathrm{~mm}$ Osypka balloon, dilation of the valve was performed (Figure 3). Post-dilation right ventricular pressure was $72 \mathrm{mmHg}$ and that of the pulmonary artery was $22 \mathrm{mmHg}$. There was mild post-dilation pulmonary regurgitation. After dilation of the valve, both catheter measurement and echocardiography showed significant subvalvar pressure gradient. The patient tolerated the procedure and there was no complication. He was extubated in the catheterization laboratory. He was discharged after one day in hospital. $\mathrm{He}$ was given propranolol $10 \mathrm{mg}$ orally 3 times a day for 3 months. His discharge echo showed reduction in the degree of tricuspid regurgitation, mild pulmonic

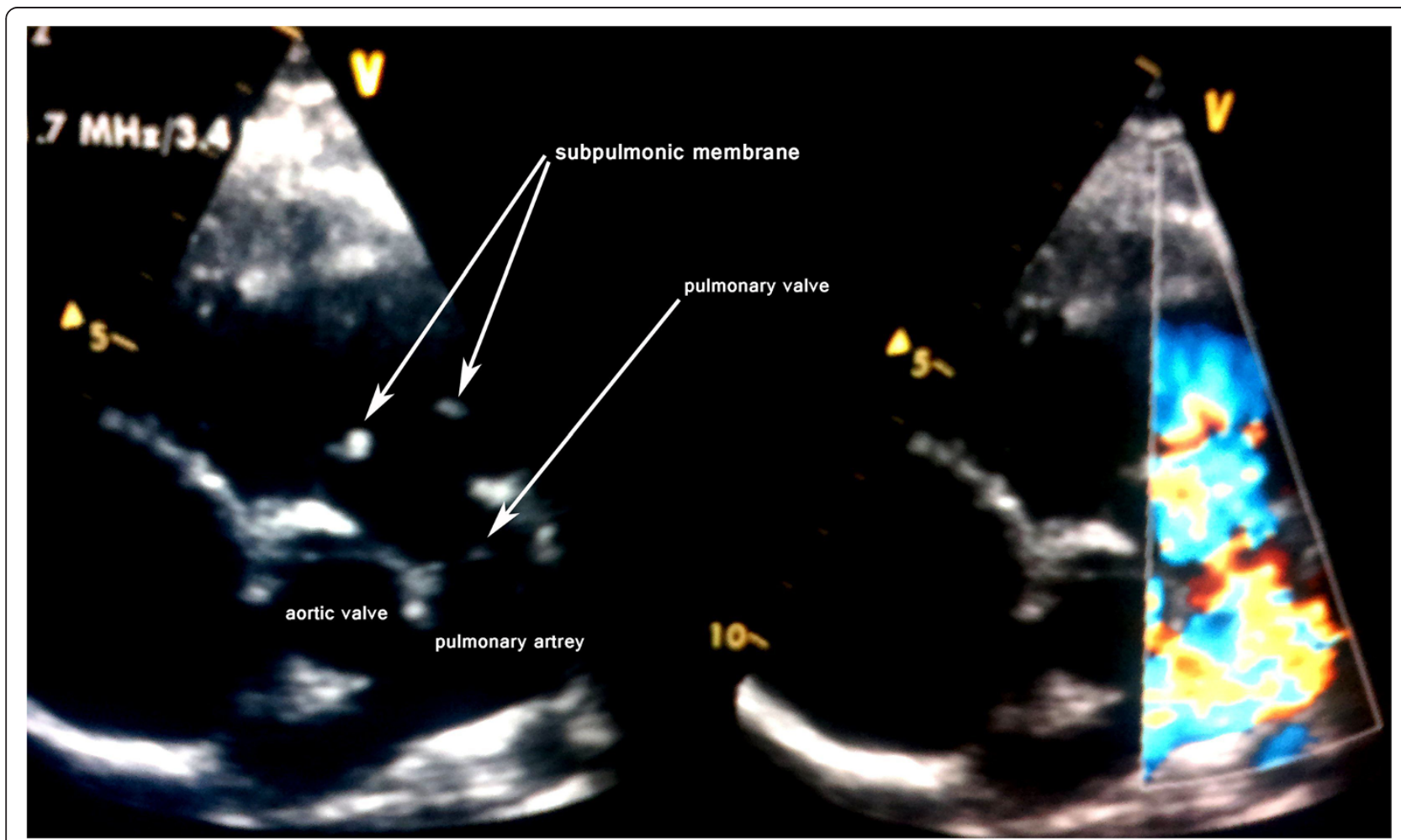

Figure 1 Two-dimensional and color flow echocardiographic frames showing discrete membrane below the pulmonary valve (post balloon dilation of the pulmonary valve). 


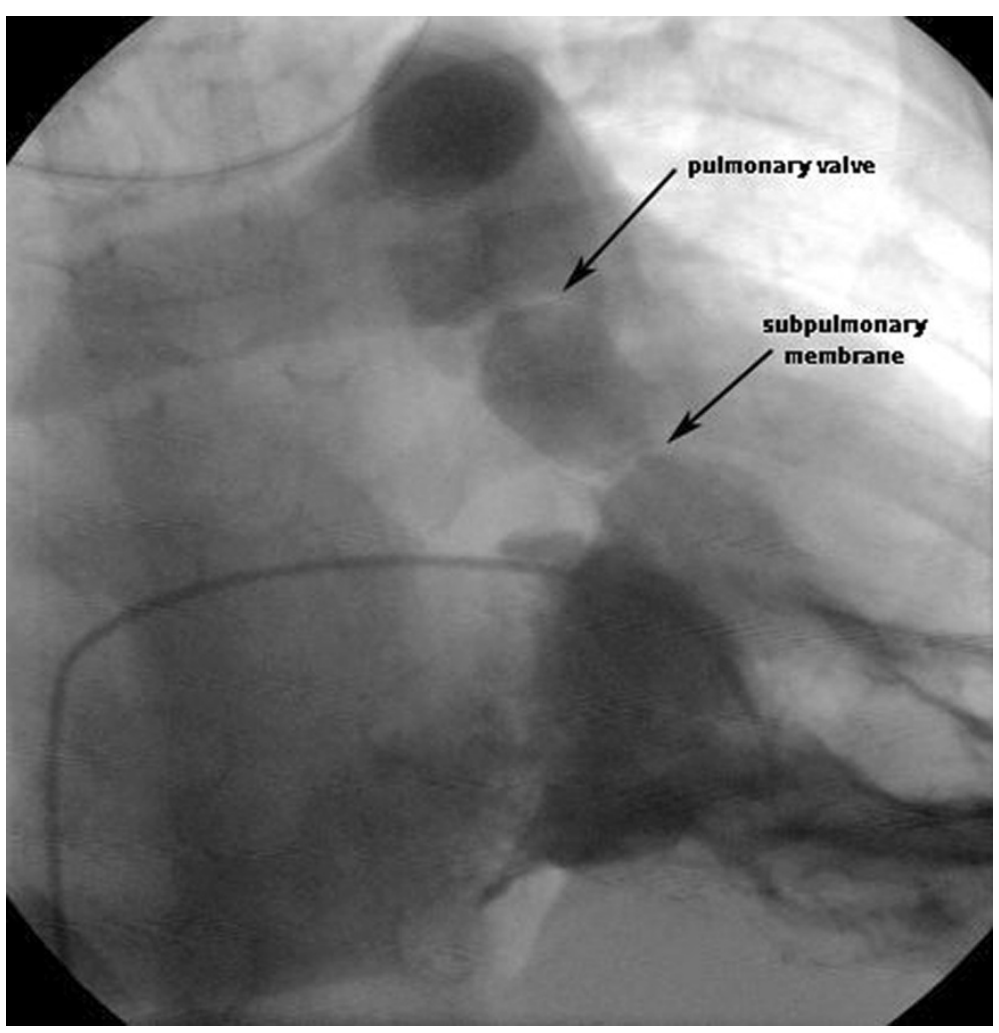

Figure 2 RV angiogram in the frontal projection with cranial angulation, showing discrete membrane below the pulmonary valve.

regurgitation and a subvalvar right ventricular outflow tract gradient of $45-50 \mathrm{mmHg}$. On a 1-month follow up visit, he reported significant improvement in his clinical symptoms and improved exercise capacity. His oxygen saturation on this visit was $95 \%$ at room air.

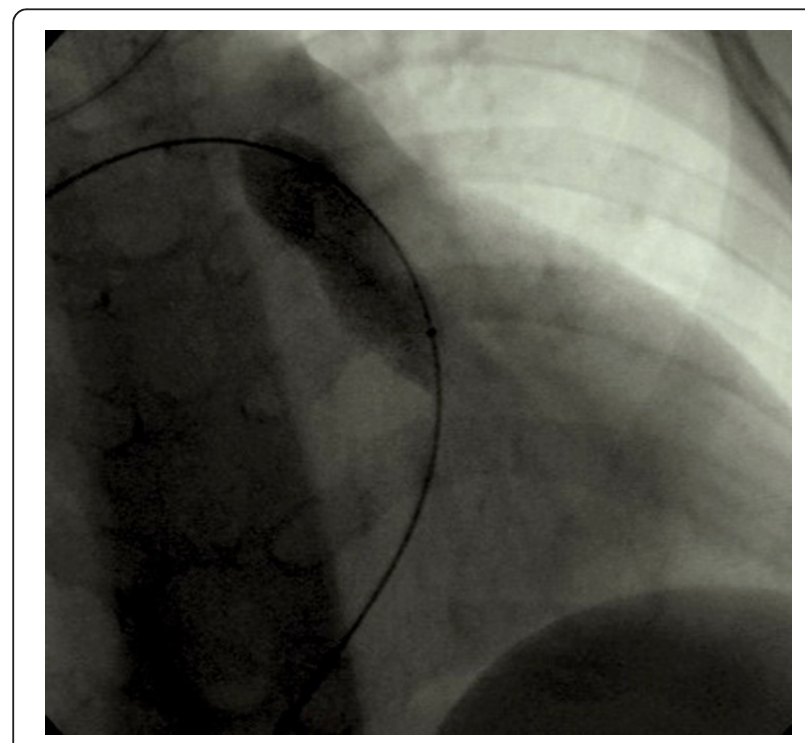

Figure $317 \mathrm{~mm} \times 30 \mathrm{~mm}$ dilation Balloon inflated across the pulmonary valve (frontal projection with cranial angulation).
His right ventricular outflow gradient on this visit was approximately $60 \mathrm{mmHg}$ and his tricuspid regurgitation has decreased in severity. His right ventricular function has improved.

\section{Discussion}

Subpulmonic obstructions are usually due to infundibular hypertrophy or subpulmonic muscle bundles. Other causes of subpulmonic obstruction reported in the literature include aneurysm of the membranous septum [5,6], aneurysmal tricuspid valve tissue in the setting of membranous ventricular septal defect [7], double-chambered right ventricle [8], and unruptured sinus of Valsalva aneurysm $[9,10]$. A single case of right ventricular outflow tract obstruction resulting from a tuberculoma in a patient with ventricular septal defect and aneurysm of the membranous septum has also been reported [11]. Subpulmonic membrane as a cause of right ventricular outflow tract obstruction is a rare occurrence [1]. Subpulmonic membrane in association with a supracristal ventricular septal defect has recently been reported by Duggal and coworkers [1]. Raff et al. also described a case of membranous subpulmonic stenosis associated with ventricular septal defect and aortic insufficiency where the membrane was incidentally noted on cardiac catheterization [2]. 
Our patient had severe pulmonary valvar stenosis with suprasystemic right ventricular pressure. With balloon dilation of the valve it was possible to lower the peak systolic pressure gradient from $185 \mathrm{mmHg}$ down to a maximum of $50 \mathrm{mmHg}$. His post dilation echo suggested that the residual gradient was mainly due to subvalvar component. Though there is a report of success in dilating the membrane itself [3], it is understandable that balloon dilation of the valve is less likely to result in complete elimination of the right ventricular outflow tract gradient. Surgery is the currently preferred modality of treatment, which can result in complete resolution of the right ventricular out flow tract obstruction [4]. The interatrial shunt could be closed at the same time. When the subpulmonic membrane is too close to the pulmonary valve one needs to be cautious, as there is a risk of damage to the valve leaflets during surgery [4]. In our patient, the surgical option may be considered in the future based on the trend of the pressure gradient on subsequent follow up visits.

\section{Conclusion}

Subpulmonic membrane as an isolated cause of right ventricular outflow tract obstruction is rare. It's association with isolated valvar pulmonary stenosis and intact ventricular septum is even less common. When such association occurs, the result of percutaneous valve dilatation may be suboptimal. Unlike the usual case of infundibular hypertrophy with valvular stenosis, membranous stenosis may not be expected to respond to beta-blocker therapy after balloon valvoplasty and such patients may need surgical intervention from the outset or after attempted balloon dilation.

\section{Consent}

Written informed consent for participation in this case study was obtained from parents of the child.

\section{Competing interests}

The authors declare that they have no competing interests.

\section{Authors' contributions}

ET: conceived the case study and design and worked on the draft manuscript. RBC: revised the manuscript critically and contributed to the content. LR: revised the manuscript critically. All authors have read and approved the final version of the manuscript.

\section{Authors' information}

ET: is a pediatric cardiologist working at the cardiac catheterization laboratory of the cardiac center Ethiopia (a charity center) within the premises of school of medicine of Addis Ababa University.

$\mathrm{RBC}$ : is an interventional cardiologist coming as a volunteer to the cardiac center, Ethiopia.

LR: is a pediatric cardiologist coming as a volunteer to cardiac center, Ethiopia.

\section{Acknowledgments}

We extend our gratitude to Dr Belay Abegaz, the founder of the Children's Heart fund of Ethiopia and the cardiac center for enabling pediatric cardiology practice in this country. We are also grateful to the staff of the cardiac center and members of the Spanish cardiac mission for their assistance. We thank Dr David Ferry of UCLA for editing the final version of the manuscript.

\section{Author details}

${ }^{1}$ Department of Pediatrics \& Child Health, School of Medicine, Addis Ababa, University \& Cardiac Center, Addis Ababa, Ethiopia. ${ }^{2}$ Department of Pediatric Cardiology, Cardiac Center Ethiopia, Ramon y Cajal University Hospital, Madrid, Spain. ${ }^{3}$ Department of Pediatric Cardiology, Cardiac Center Ethiopia, La Paz Hospital, Madrid, Spain.

Received: 11 February 2013 Accepted: 19 June 2013

Published: 21 June 2013

\section{References}

1. Duggal B, Bajaj M, Bansal NO: Subpulmonic Membrane Associated with a Supracristal VSD: A rare cause of right ventricular outflow obstruction. Echocardiography 2011, 28:E89-E90.

2. Raff GW, Gaynor JW, Weinberg PM, Spray TL, Gleason M: Membranous subpulmonic stenosis associated with ventricular septal defect and aortic insufficiency. J Am Soc Echocardiogr 2000, 13:58-60.

3. Vasec $J$, Goertz KK: Balloon Valvuloplasty of a subpulmonic membrane. Am Heart J 1990 Jun, 119(6):1419-1421.

4. Tomar M, Radhakrishnan S, Sharma R: Isolated subpulmonary membrane causing critical neonatal pulmonary stenosis with concordant atrioventricular and ventriculoarterial connections. Images in Pediatr Cardiol 2009, 11(3):5-9.

5. Gunawan A, Krajcer Z, Leachman RD: Aneurysm of the membranous septum causing outflow obstruction of the venous ventricle in corrected transposition of the great arteries. Tex Heart Inst J 1982, 9(1):91-95.

6. Santos de Soto J, Lillo Jimenez T, Lopez Haldon J, Gonzalez Brrero A, Alvarez Madrid A: Subpulmonary obstruction caused by an aneurysm of the membranous ventricular septum. A study of 2 cases (abstract). Rev Esp Cardiol 1999, 52(5):351-354.

7. Eason DE, Allen DR, Ganjemi JJ, Moskowitz WB: Subpulmonic obstruction by aneurysmal tricuspid valve tissue in a perimembranous ventricular septal defect. J Am Coll Cardiol 2012, 60(4):355.

8. McElhinney DB, Chatterjee KM, Reddy VM: Double-chambered right ventricle presenting in adulthood. Ann Thorac Surg 2000, 70:124-127.

9. Liang $C D$, Chang JP, Kao CL: Unruptured sinus of Valvsalva aneurysm with right ventricular outflow tract obstruction associated with ventricular septal defect. Cathet Cardiovasc Diagn 1996, 37(2):158-161.

10. Thankachen R, Gnanamuthu R, Doshi H, Shukla V, Korula RJ: Unruptured Aneurysm presenting with right ventricular outflow tract obstruction. Tex Heart Inst J 2003, 30:152-154.

11. Santos CL, Moraes F, Moraes CR: Obstruction of the right ventricular outflow tract caused by a tuberculoma in a patient with ventricular septal defect and aneurysm of the membranous septum. Cardiol Young 1999, 9(5):509-511.

doi:10.1186/1471-2261-13-43

Cite this article as: Tefera et al:: Discrete subpulmonic membrane in association with isolated severe pulmonary valvar stenosis. BMC Cardiovascular Disorders 2013 13:43.

\section{Submit your next manuscript to BioMed Central and take full advantage of:}

- Convenient online submission

- Thorough peer review

- No space constraints or color figure charges

- Immediate publication on acceptance

- Inclusion in PubMed, CAS, Scopus and Google Scholar

- Research which is freely available for redistribution 